In the $1920 \mathrm{~s}$ Warrington Yorke had pioneered the malarial treatment of G.P.I. and neurosyphilis. It was Warrington Yorke who foresaw the dangers of Japanese intervention in the last war, and the overrunning of Java, the major source of the world's supply of quinine. It was his enthusiasm and energy which led the Governments of the U.K. and U.S.A. to provide mepacrine, which had been developed as an antimalarial drug in the inter-war period, so that by 1942 there were adequate supplies to forestall disaster. Warrington Yorke played an important part in the testing of Paludrine, and it was his method of maintaining trypanosomes alive in culture which led the way to the treatment of sleeping sickness and kala-azar with the diamidine group of compounds. Indeed, Wenyon, in the obituary notice on Yorke written for the Royal Society, observed: "He had been instrumental in introducing for the treatment of two of the most intractable tropical diseases remedies which will lead to the saving of many human lives."

\section{Neurophysiology}

Measured in terms of fundamental contributions to knowledge the brightest star of the Liverpool firmament was Charles Scott Sherrington-the greatest physiologist since Harvey and "the philosopher of the nervous system." I have described in my monograph on Sherrington how, between 1895 and 1913, when he occupied the George Holt Chair of Physiology in Liverpool, he laid the foundations of neurophysiology. His work is so well known as physiologist, philosopher, and poet that I do not propose further to refer to it. But one of his predecessors in the Chair of Physiology, Richard Caton, who was a physician on the staff of the Royal Infirmary, Lord Mayor of Liverpool, and one of the founders both of University College, Liverpool, and of the Tropical School, carried out fundamental work on the electrophysiology of the nervous system which anticipated modern electroencephalography. I have paid a tribute to his contributions in a paper to the Section of History of the Royal Society of Medicine.

\section{Conclusion}

Time has permitted reference to but a tithe of those in the history of the Liverpool School of Medicine who have made lasting contributions to knowledge. In any comprehensive survey it would have been necessary to mention that in Liverpool was started by William Rathbone (aided by Florence Nightingale) the first District Nursing Association; that in 1902 Liverpool established the first chair of biochemistry in the world, and appointed to it Benjamin Moore ; that in Liverpool diagnostic radiology was very early established by Thurstan Holland, who became the first President of the International Congress of Radiology, and established the first diploma and degree in radiology ; that the Royal College of Obstetricians and Gynaecologists owes its birth to Blair Bell, who was its first president. Indeed, the pioneering spirit of Liverpool in medicine is almost endless.

A pessimistic critic at the end of the eighteenth century wrote of Liverpool: "Art and science are inimical to the spot; absorbed in the nautical vortex, the only pursuit of the inhabitants is commerce. Liverpool is the only town in England of any pre-eminence, that has not one single erection or endowment for the advancement of science, the cultivation of the arts or promotion of useful knowledge. It may truly be said with the son of Sirach, that wisdom cries out in the streets and no man regards it."

Enough, however, has now been said of Liverpool's medical achievements in the past 150 years to obliterate the stain, and to pardon the inordinate pride that Wilfrid Edgecombe must have felt at being an alumnus of a School to which humanity owes so great a debt.

\title{
Surgical Treatment of Carcinoma of the Bronchus
}

\author{
J. R. BELCHER,* M.S., F.R.C.S. ; R. ANDERSON,* ${ }^{*}$ M.B.
}

Brit. med. F., 1965, 1, 948-954

During the past 15 years the incidence of carcinoma of the bronchus has more than doubled in Great Britain. Although lamentably few patients are found to be amenable to any sort of treatment, resection still offers the best hope of cure. A study has therefore been made of the patients who were admitted to hospital with bronchial carcinoma under the care of one of us (J.R. B.), and who had a thoracotomy done during this period.

These patients have been reviewed to see how the pattern of the surgical treatment has changed in these 15 years, whether there has been any change in some aspects of the disease itself, what the survival rate has been, and some of the factors that might have influenced it.

\section{Policy}

The policy on which the surgery was based changed little during the 15 years under review. Apart from general metastases, the contraindications to surgery were, with few excep-

\footnotetext{
* London Chest Hospital.
}

tions, as follows: phrenic-nerve paralysis and recurrent laryngeal paralysis (but not Horner's syndrome or Pancoast's syndrome); superior vena caval obstruction and radiologically visible right paratracheal glands in left-sided lesions; bloodstained pleural effusions (but not clear effusions), the assumption being that these were due to widespread pleural secondaries ; and invasion of the trachea by tumour, but not invasion of the chest wall.

Apart from these phenomena, due to the disease itself, respiratory insufficiency was the commonest reason for advising against thoracotomy. A forced expiratory volume in one second of less than 1,200 ml. and a forced expiratory ratio of less than $50 \%$ were regarded as the " borderline," and in general it was felt that if a patient's respiratory function precluded pneumonectomy it probably made the risk of lobectomy too great as well. It is in this field chiefly that the indications for surgery have narrowed in the period under review.

Advancing age was no bar to surgery, although, as the figures show, the results in patients over the age of 70 were poor, and increasing awareness of this recently led to more hesitancy in recommending surgery in this age group. 
The cell type of tumour found at biopsy or cytological examination of the sputum was not allowed to influence the recommendation for surgery, except in a few marginal cases where oat-celled tumours were found. The wisdom of this policy was recently confirmed when it was found that the error in typing biopsy specimens might be as high as one in three (Deal and Belcher, 1963). At the other end of the scale, thoracotomy was always recommended for patients with shadows visible on their radiographs when there was the slightest chance that the shadow might be due to a carcinoma.

At operation the policy, almost from the beginning, was "lobectomy where possible." There was a steady increase in the proportion of lobectomy to pneumonectomy as the years went by, until lobectomy became the commoner form of resection in 1959. By this time Nohl (1956) had shown that " radical" lobectomy with the removal of the draining lymph nodes was possible, and Cotton (1959) had demonstrated that the spread of the carcinoma in the bronchus itself was not wide, and that conservatism was justifiable on that score. Sleeve resection (Johnston and Jones, 1959) was not widely practised, and the number in this series was of negligible significance. The nine segmental resections which were done have been included for statistical purposes under "lobectomy"; the three patients in whom residual lobectomy was done have been included under pneumonectomy.

The policy of Abbey Smith (1957), who recommends resection in almost every patient who has a thoracotomy, was not adopted. In general, if there was widespread invasion of the mediastinal structures the condition was regarded as inoperable and the chest was closed. The resection rate remained fairly constant throughout the series, although it was a little higher recently (Fig. 1).

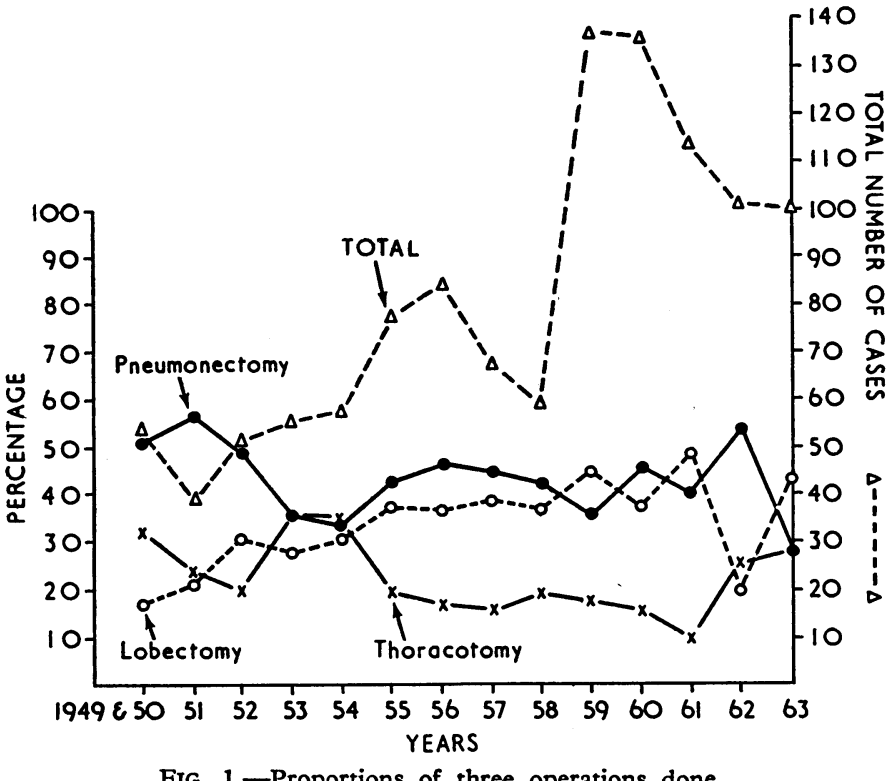

Fig. 1.-Proportions of three operations done.

Lastly, at various times during the 15 years series of investigations were conducted, using some of the various adjuncts to surgery (MacFarlane et al., 1962 ; Sturridge, 1964 ; Crosbie et al., 1965). These included radiotherapy in a group of patients who had a lobectomy ; nitrogen mustard for another controlled series who had all forms of operation; and vinblastine sulphate (Velbe) for a similar group. None of these seem on review to have had a significant influence on the results.

\section{Patients and Methods of Study}

Data from 1,134 patients have been reviewed. They were operated on at the London Chest, the Middlesex, and Pinewood Hospitals between January 1949 and December 1963 : 633 were operated on by one of us (J.R. B.) ; the remainder were done by his assistants.

The data collected were as follows: age at operation, sex, date and type of operation, cell type and site of tumour, and the extent of glandular involvement. In a few of the earlier cases information about the pathological details was not available.

Follow-up data are available in all except 14 (1\%) of the patients. If they have died, the date of death and hence the length of survival have been recorded. The remainder were either seen or written to in 1963 at or near to the anniversary of their operation. They have been recorded as survivors if they were alive at that time. Those patients who lived more than one year after their operation and subsequently died have been recorded as survivors up to the last anniversary of their operation before they died.

\section{Operative Mortality}

Patients who died before leaving hospital have been recorded as operative deaths. The operative mortality for the whole series of resections was $10 \%(91 / 896)$; for pneumonectomy it was $14 \%(66 / 480)$, and for lobectomy $6 \%(25 / 416)$. In those who had a thoracotomy only the mortality was much lower, $4 \%$ (9/238).

The operative mortality has changed little during the period under discussion, apart from a sharp rise in 1957-8 and a fall to $4 \%$ in 1963 (Fig. 2). This is disappointing, as the methods for resuscitation, particularly from cardio-respiratory failure, have improved a lot in the last five years, and it might have been expected that this would have lessened the operative risk.

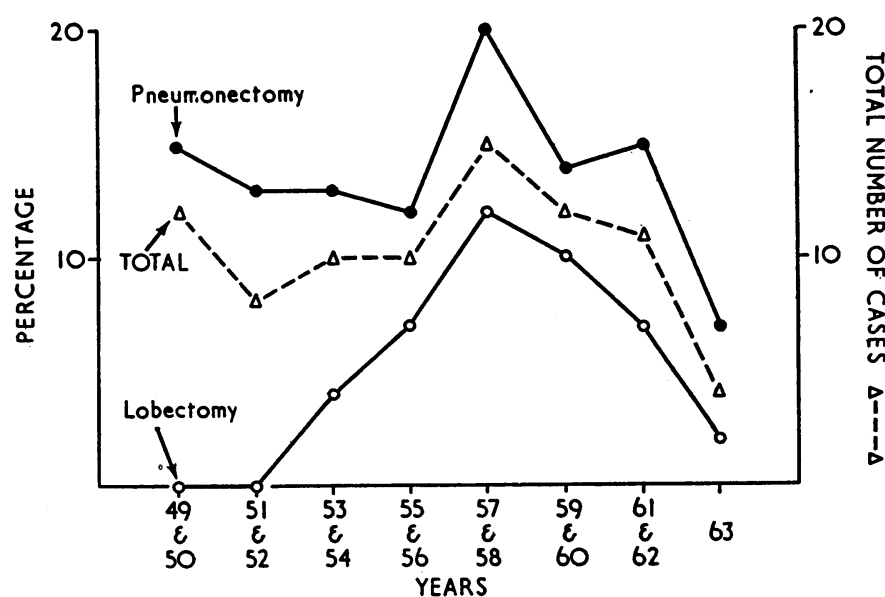

FIG. 2.-Operative mortality year by year.

It is not always easy to determine the exact cause of death after operation, and some deaths may have been due to unrecognized broncho-pleural fistulas (Sturridge, 1964), but the causes of death so far as could be ascertained, and often confirmed by necropsy, are set out in Table I.

TABle I.-Causes of Operative Death (Percentages to Nearest Unit)

\begin{tabular}{|c|c|c|c|c|}
\hline & Pneumonectomy & Lobectomy & Thoracotomy & Total \\
\hline Respiratory insufficiency ... & $\begin{array}{l}13 \\
11\end{array}$ & $\begin{array}{l}8 \\
4\end{array}$ & $\begin{array}{l}3 \\
1\end{array}$ & $\begin{array}{l}24 \\
16\end{array}$ \\
\hline $\begin{array}{l}\text { Broncho-pleural fistula and } \\
\text { empyema } \\
\text { Pulmonary embolus }\end{array}$ & $\begin{array}{r}13 \\
5\end{array}$ & $\begin{array}{l}2 \\
2\end{array}$ & 1 & $\begin{array}{r}16 \\
7\end{array}$ \\
\hline $\begin{array}{lll}\text { Others } & & \\
\text { Not recorded } & \cdots & \because\end{array}$ & $\begin{array}{r}18 \\
6\end{array}$ & 9 & 4 & 31 \\
\hline
\end{tabular}

Respiratory insufficiency was the commonest cause of death ; it was responsible for a third of those in patients who had a lobectomy. This group included those cases where the operation was aimed at palliation, because it was thought that 
pneumonectomy was not justified on the grounds of inadequacy of respiratory function. This finding supports the suggestion that if a patient is unfit for pneumonectomy because of respiratory insufficiency he may well be also unfit for lobectomy. Gifford and Waddington (1957) also stressed the importance of cardio-respiratory failure as the chief cause of death after resection. It accounted for almost two-thirds of their operative deaths, and the proportion among their patients who had a lobectomy was almost as high as that in those with a pneumonectomy.

The number of deaths due to haemorrhage was high, and this should be avoidable. On the other hand, the number due to pulmonary emboli was low for patients in this age group having major surgery. They were almost all operated on in the prone position, and it is thought possible that this may have been responsible for a gratifyingly low figure of less than $1 \%$.

Overt broncho-pleural fistulas and empyemas were also surprisingly infrequent causes of death, although the small unrecognized fistulas may have been responsible for some of the deaths ascribed to respiratory insufficiency.

Lastly, although lobectomy being a less severe operation necessarily carries a lower risk, the disparity between it and pneumonectomy lessened as the years passed (Fig. 2).

\section{Survival}

The survival rates have been set out as follows: Actual survival

Possible survival $\times 100$. Those who died at operation have been excluded from the group of possible survivors. Thus if 100 patients were operated on in any one year, and there were 10 deaths at operation, then if 45 patients lived two years and 18 lived five years the survival rates would be recorded as $50 \%$ and $20 \%$.

\section{Thoracotomy}

Those patients who were regarded as inoperable at thoracotomy constituted $21 \%$ of the whole series. Although they had a low operative mortality, the prognosis was very bad indeed: only one lived for five years ; she had had radiotherapy. Only $3 \%$ of those at risk survived two years, and $77 \%$ were dead in less than one year after their operation. The average length of survival after operation for all these patients worked out at the terribly short time of nine months.

\section{Resection}

In all, 896 resections were done: they were 480 pneumonectomies $(53 \%)$ and 416 lobectomies (47\%). The survival

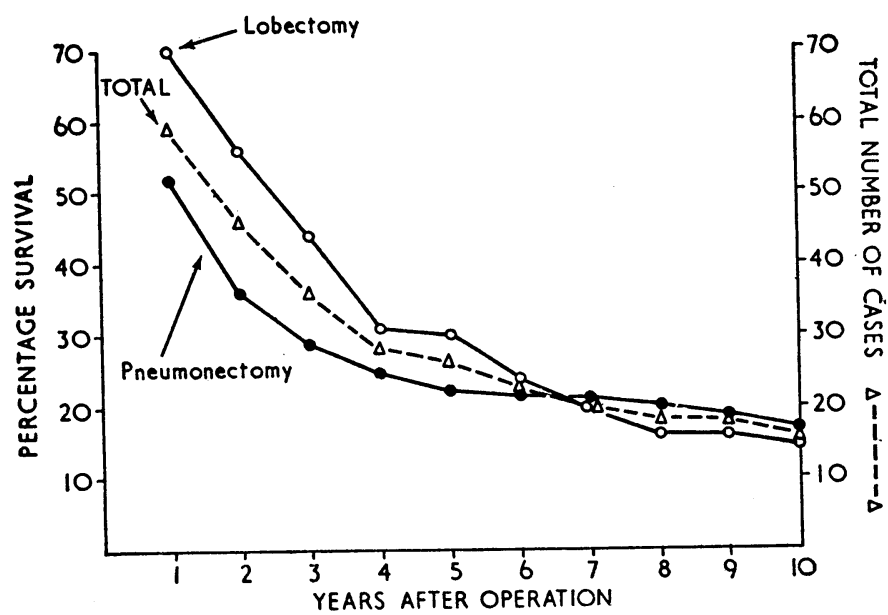

FIG. 3.- Survival after operation, excluding operation mortality. rates at five years for the patients in whom a resection was possible was $26 \%$ (93 out of 356 ). It was $29 \%$ where a lobectomy had been done ( 46 out of 157 ), but only $24 \%$ after a pneumonectomy (47 out of 199). After two years the rates were $46 \%$, $56 \%$, and $36 \%$ respectively.

The rates fell slowly after five years (Fig. 3), and at 10 years the rate was still as high as $16 \%$ (21 out of 130). Even after this time the rate fell slowly, but the number of patients at risk was small.

Of the 23 patients who lived six years or more after their operation and who subsequently died, 13 certainly did so from causes other than bronchial carcinoma, but two who lived 10 and 12 years eventually died from metastases. Thus the majority who were going to die as a result of the carcinoma had done so within five years of their operation. Expressed in another way, the follow-up showed that if a patient lived for two years after an operation for bronchial carcinoma he had a $33 \%$ chance of living 10 years, and that if he had lived for five years after his operation his chance of living 10 years was even better $(57 \%)$.

The figures were a little different for lobectomy and for pneumonectomy (Fig. 3) in that the early survival rates for the less extensive operation were better, but after seven years there was virtually no difference between them.

\section{Influence of Age}

During the 15 years under consideration there was no change in the proportion of patients in each decade operated on. The percentages in each group are shown in Fig. 4.

Two groups at the opposite ends of the scale have been separated for special study-those over $70^{\circ}$ years of age and those under 45 . There were 92 patients under 45 . This upper limit was chosen because there were only 20 under 40 years, and this was thought to be too small a number to provide useful information. Of the $92,22(24 \%)$ were women. The proportion was more than double that in the whole series $(10 \%)$.

The cell type of the tumours was similar to that in the rest of the patients, but because of the higher proportion of women the proportion of adenocarcinomas was greater (Table II).

TABLE II.-Comparison of Three Special Groups (Percentages to Nearest

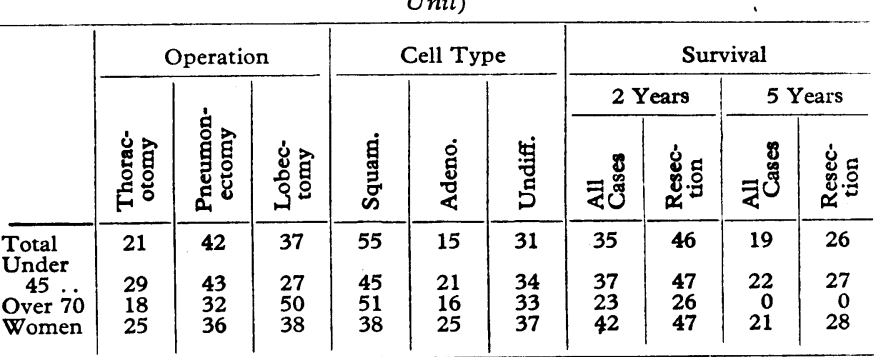

The operative mortality was nil, but a higher proportion of thoracotomies only was done and a lower proportion of lobectomies. Those patients in whom a resection was done had a survival rate almost identical with that of the whole series at two and at five years. Kwong and Slade (1964) also report a low resection rate in a group of patients under 40 , but the five-year survival rate in their patients in whom resection was possible was $45 \%$. Thus, contrary to expectations, the younger patients were found to have as good a prognosis as the remainder. This was also true amongst the smaller groups under 40 , and the youngest patient in the series, who was 25 when he had his undifferentiated tumour removed nine years ago, is still alive and well. Histological re-examination confirmed the original diagnosis. 
At the other end of the scale there were 50 patients who were 70 or more when they had their operation. They did so badly that the wisdom of operating on patients of this age group may well be questioned. There were five women; the cell type of the tumours was similar to that of the whole series (Table II). The resectability rate was a little better than average, and a higher proportion of lobectomies were done. Six patients died immediately after operation, five had had a pneumonectomy; the mortality for this particular operation was thus $33 \%$ in this age group. The survival rates were very low ; one-quarter lived two years, and not one survived for five years. The expectation of life of a man aged 70 is nine years, and only six of the 29 patients who died after leaving hospital were known to have died of causes other than carcinoma. Thus the disease seems to lose none of its malignancy when it affects older people ; the reverse seems to be the case.

\section{Women}

There were 113 women operated on; this was $10 \%$ of the whole series, and the percentage had not changed appreciably throughout the period under review. The average age was a little lower than that of the men because there were more under the age of 50, and the peak between the ages of 50 and 60 was not nearly so marked as it was among the men (Fig. 4).

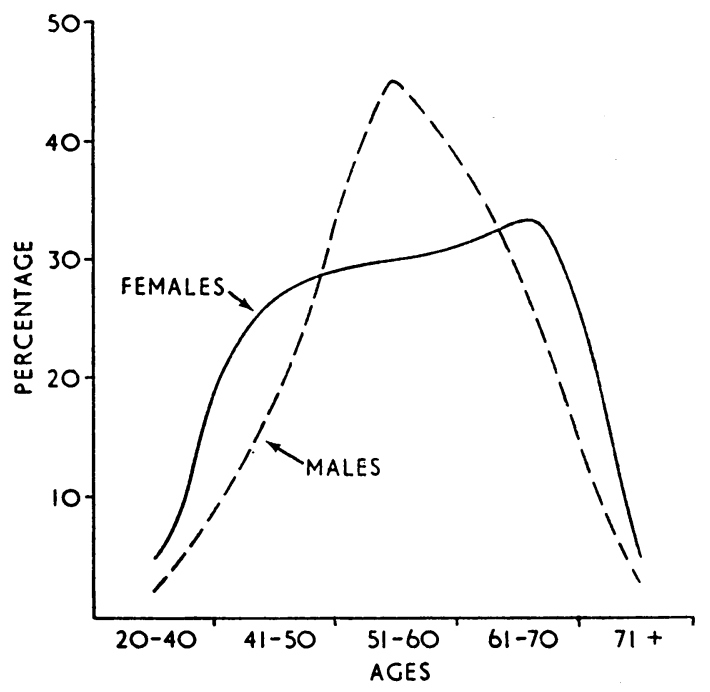

FIG. 4.-Age incidence of patients.

It was found that adenocarcinomas were commoner among the women ; this type of tumour constituted $25 \%$, as compared with $15 \%$ in the whole series. This rise corresponded with a considerable fall in the proportion of squamous-cell carcinomas.

The operative mortality was the same as that for the whole series, and the proportions of the three types of operations were almost the same (Table II). The two-year and the five-year survival rates were slightly better, and they were almost the same as those for the patients under the age of 45 .

\section{Site}

In $51 \%$ of the patients the carcinoma was on the right side, but, less predictably, it was found that $57 \%$ had tumours in the upper lobes (Table III). Much the largest number were in

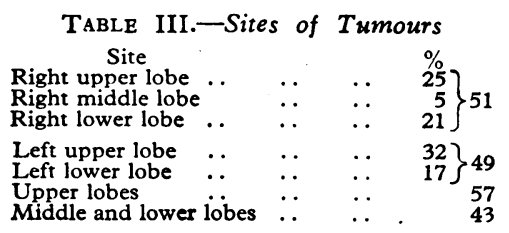

the left upper lobe, totalling about the same as those in the right upper and middle lobes combined. On the other hand, the number operated on with left lower-lobe tumours was surprisingly small $(17 \%)$.

There was no difference in the sex incidence in the various lobes. The operative mortality was highest in the few cases where the middle lobe was involved $(23 \%)$, and much the lowest when the left upper lobe was affected (3\%).

A higher proportion of lower-lobe tumours were removed than upper- and middle-lobe ones ( $82 \%$ compared with $75 \%$ ). Pneumonectomy was most often needed for left lower-lobe and for middle-lobe lesions, whereas lobectomy was most of ten possible for right upper-lobe and lower-lobe tumours (Table IV).

TABLE IV.- Site of Tumour and Operation Performed

\begin{tabular}{rll|c|c|c}
\hline \multicolumn{1}{r|}{ Site } & & & Thoracotomy & Pneumonectomy & Lobectomy \\
\hline Right upper lobe &. & $\ldots$ & $22 \%$ & $36 \%$ & $42 \%$ \\
Right middle lobe & $\cdots$ & $\ldots$ & $28 \%$ & $50 \%$ & $22 \%$ \\
Right lower lobe & $\cdots$ & $\ldots$ & $18 \%$ & $41 \%$ & $41 \%$ \\
Left upper lobe & $\cdots$ & $\ldots$ & $26 \%$ & $40 \%$ & $35 \%$ \\
Left lower lobe & $\cdots$ &.. & $18 \%$ & $53 \%$ & $28 \%$ \\
\hline
\end{tabular}

The histology of the tumours found in the various lobes showed that the proportions varied remarkably little except in the case of the middle-lobe tumours, where the figures were necessarily small. It was also found that the survival rates for tumours in the different lobes was very similar both after two and after five years.

\section{Cell Type}

Histological reports were available in 1,061 of the 1,134 patients. The majority of the remainder had thoracotomies early in the series, during which no biopsy was taken. The classification in the three hospitals concerned was the samenamely, squamous-cell carcinoma, undifferentiated carcinom $\varepsilon$ and adenocarcinoma. The oat-cell tumours were considerec under the heading of the undifferentiated tumours, although they were separated in another report (Deal and Belcher, 1963. concerning some of the patients in this series.

Of the tumours, $55 \%$ were squamous-celled, $31 \%$ were undifferentiated, and $15 \%$ were adenocarcinomas. The serie: was broken down into periods of two years to find out $i$ there had been any change in the proportions of the tumour: in the 15 years under review. A change might have been expected if there was some dominant aetiological factor in -one or more of the histological types, as the incidence of the disease and the number of patients treated each year had risen con-

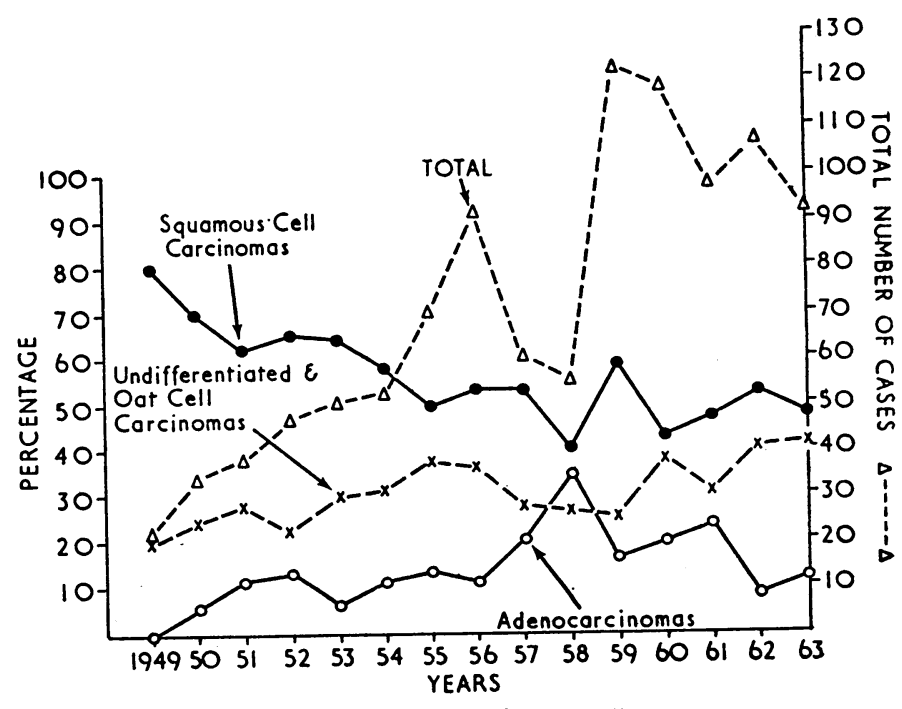

FIG. 5.-Annual proportion of cell types. 
siderably during the time. It was found that there had been such a change (Fig. 5). The number of undifferentiated tumours had risen at the expense of the squamous-cell tumours. This had occurred at each of the hospitals concerned, and was not therefore confined to the findings of one pathologist. Apart from the year 1958, the proportion of adenocarcinomas had not changed significantly over the years, but the actual number had risen pari passu with the other tumours, from 6 in the first three years to 18 in 1962-3.

The operations done for the patients with tumours of the three different cell types are shown in Table V. This shows that a higher proportion of patients with adenocarcinomas were able to have a resection done $(90 \%)$, and that the lowest proportion of resections was among those with undifferentiated tumours $(70 \%)$. Lobectomy was highest in those with adenocarcinomas, and again lowest in those with undifferentiated tumours. The percentage of glandular metastases was highest in those with undifferentiated tumours, and lowest in these with adenocarcinomas (see Table VII). These findings are similar to those in other series.

\begin{tabular}{|c|c|c|c|c|}
\hline & $\begin{array}{l}\text { Total } \\
\text { No. }\end{array}$ & $\begin{array}{l}\text { Thora- } \\
\text { cotomy } \\
(\%)\end{array}$ & $\begin{array}{l}\text { Pneumon- } \\
\text { ectomy } \\
(\%)\end{array}$ & $\begin{array}{l}\text { Lobec- } \\
\text { tomy } \\
(\%)\end{array}$ \\
\hline Squamous carcinoma $\ddot{0}$. & 577 & 15 & 47 & 37 \\
\hline 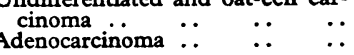 & $\begin{array}{l}325 \\
159\end{array}$ & $\begin{array}{l}30 \\
10\end{array}$ & $\begin{array}{l}41 \\
34\end{array}$ & $\begin{array}{l}29 \\
56\end{array}$ \\
\hline
\end{tabular}

The patients with squamous carcinomas had the best prognosis. At two years the worst survival rate was among those with undifferentiated tumours ; this reflected the lower resectability rate, and the higher proportion with glandular metastases. At five years the differences were less marked (Table VI): those with squamous-celled tumours had the best rate ( $23 \%$ of all cases), and those with adenecarcinomas had the worst. Although the numbers in the latter group were small, the figures were probably large enough to confirm the opinion that the adenocarcinoma is by no means the least malignant of the three.

TABLE VI.-Survival According to Cell Type (Percentages to Nearest

\begin{tabular}{ccc|c|c|c|c|c}
\hline & & \multicolumn{2}{|c|}{2 Years } & \multicolumn{2}{c}{5 Years } \\
\cline { 3 - 7 } \cline { 5 - 7 } & & All Cases & Resections & All Cases & Resections \\
\hline Squamous carcinoma &. &. & 42 & 40 & 23 & 29 \\
Undifferentiated and oat cell &. & 22 & 32 & 17 & 25 \\
Adenocarcinoma &.. &.. &. & 38 & 43 & 16 & 16 \\
\hline Total .. &.. &.. &. & 35 & 46 & 19 & 26 \\
\hline
\end{tabular}

In the large series recently published by Clagett et al. (1964) the five-year survival rates were much better than those reported here, and differed for the various cell types. The best rate was among those patients with squamous-cell carcinomas $(38 \%)$, next in adenocarcinomas $(36 \%)$, then in undifferentiated tumours $(29 \%)$, but almost nil in those with oat-cell tumours.

Lastly, the influence of glandular involvement on the prognosis was studied. It was found that the two-year and five-

TABLE VII.-Influence of Glandular Involvement on Prognosis After TABLE VII.-Influon (Percentages to Nearest Unit)

\begin{tabular}{|c|c|c|c|c|c|}
\hline & \multirow[b]{2}{*}{ Glands } & \multicolumn{2}{|c|}{2 Years } & \multicolumn{2}{|c|}{5 Years } \\
\hline & & Involved & $\begin{array}{c}\text { Un- } \\
\text { involved }\end{array}$ & Involved & $\begin{array}{c}\text { Un- } \\
\text { involved }\end{array}$ \\
\hline Squamous carcinoma & 51 & 35 & 62 & 19 & 33 \\
\hline $\begin{array}{cc}\text { Undifferentiated } & \text { and } \\
\text { oat-cell } . . & \ldots \\
\text { Adenocarcinoma } & \ldots\end{array}$ & $\begin{array}{l}66 \\
42 \\
\end{array}$ & $\begin{array}{l}23 \\
19 \\
\end{array}$ & $\begin{array}{l}43 \\
57 \\
\end{array}$ & $\begin{array}{l}13 \\
10 \\
\end{array}$ & $\begin{array}{l}37 \\
21 \\
\end{array}$ \\
\hline Total $\quad$. & & 29 & 58 & 16 & 33 \\
\hline
\end{tabular}

The number of patients with adenocarcinoma at risk was small, which may have accounted for the wide variations in this type. year survival rates in the patients who had resections done were $58 \%$ and $33 \%$ when the glands did not contain metastases, and $29 \%$ and $16 \%$ when they did (Table VII). The highest five-year survival rate was among those who had a resection for an undifferentiated tumour with glands free from metastases $(37 \%)$.

\section{Comparison of Two Groups}

There were 633 patients operated on by one of us (J.R. B.), and 501 by his assistants. A comparison was made between the two series to see if there was any significant difference between them, as the method of selection for operation was identical for them both.

There were no important differences between the ages, the sex ratio, the sites, or the proportion of the cell types of the tumours in the two series. There was a significant difference between the proportions of the types of operation done. The resection rate among the patients operated on by the assistants was $84 \%$, compared with $75 \%$ in the other group. There was no difference between the proportions of lobectomies done, and thus the figures indicate a more aggressive policy among the assistants, who did $9 \%$ more pneumonectomies in the patients who would have been regarded as inoperable by J.R. B. This difference was reflected in the results in two ways. First, the operative mortality was higher in the group in which there was a higher proportion of resections ( $12 \%$ as against $8 \%$ ), but, as might have been expected, the difference lay almost entirely among those who had a pneumonectomy done $(16 \%$ as against $10 \%$ ), because this included those who would have been rejected as inoperable in the group with the lower resection rate. Secondly, there was a slightly lower survival rate at two years in the series with the higher resection rate $(45 \%$ as against $48 \%$ ), but this difference had disappeared at five years after the operations.

\section{Discussion}

The annual mortality from bronchial carcinoma has gone up in this country from 11,000 to 23,000 in the past 15 years. It might be expected that the factors responsible for this appalling increase would not affect all aspects of the disease to the same extent. However, this study of patients submitted to an operation for the condition has shown that the general pattern has changed little during the time, for the age of presentation was unchanged, the sex ratio remained constant at one woman to every nine men, and the results of surgery have scarcely improved.

There has been some alteration in the relative proportion of the three cell types into which the tumours have been classified in this series. There was a rise in the percentage of the undifferentiated tumours at the expense of that of squamous tumours (Fig. 5). This difference was seen at each hospital at which the patients were treated, suggesting that the change was a real one, and that it was not due to variation of the classification of one pathologist. The proportion of adenocarcinomas remained much the same throughout, although the total number of cases each year increased. This finding is unexpected, for if the main contributory factor in the increase of bronchial carcinoma was smoking, the proportion of adenocarcinomas should have fallen, for Kreyberg (1962) has shown that smoking is not related to the incidence of adenocarcinoma, though it is to the other types. It also might have been expected that if smoking had a more pronounced aetiological role in men than in women, then the proportion of women should have fallen during the 15 years. This did not happen.

In previous series the operative mortality has varied widely, but has been lower in those more recently published. In our series, although there has been a significant fall in the last four years, the operative mortality has remained disappointingly 
high, despite improved post-operative care with the introduction of assisted respiration and the newer antibiotics.

The resection rate in the larger published series has varied between $47 \%$ (Barrett et al., 1963) and 95.4\% (Abbey Smith, 1964 ) ; in our series it was $79 \%$ (Table VIII). It might be expected that the survival rate after resection would be higher in those with the lowest resection rate, since the group in which the resection had been done would include more patients at an early stage of the disease. This is shown in the series published by Abbey Smith (1964), in which the resection rate was $95.4 \%$ and the survival rate was $20.5 \%$. This figure is almost the same as that for all the cases described here, including those who did not have a resection $(21 \%)$. The expected correlation between the resection rate and the survival rate was also seen in the earlier cases in this series, but in more recent years the correlation has not been so close (Fig. 6), and indeed the two-year survival rate has recently risen considerably, despite an increase in the proportion of thoracotomies. Lastly, it was shown that, despite the higher resection rate in the cases treated by the assistants among those reported here, the fiveyear survival rate was unaltered.

In most of the other series and among those described as having had "standard" resections by Abbey Smith the survival rate has been very similar whatever the resection rate (Table VIII). These observations suggest that little is lost by the adoption of an aggressive policy in the treatment of bronchial carcinoma, and that in a few cases of advanced disease benefit may be achieved.

The fact that neither the resectability rate nor the survival rates have improved significantly during the 15 years under review emphasizes that there is still considerable scope for improvement in the selection of patients for thoracotomy, as there seems little prospect that any advance in operative technique will lead to better results in long-term survival.

TABLE VIII

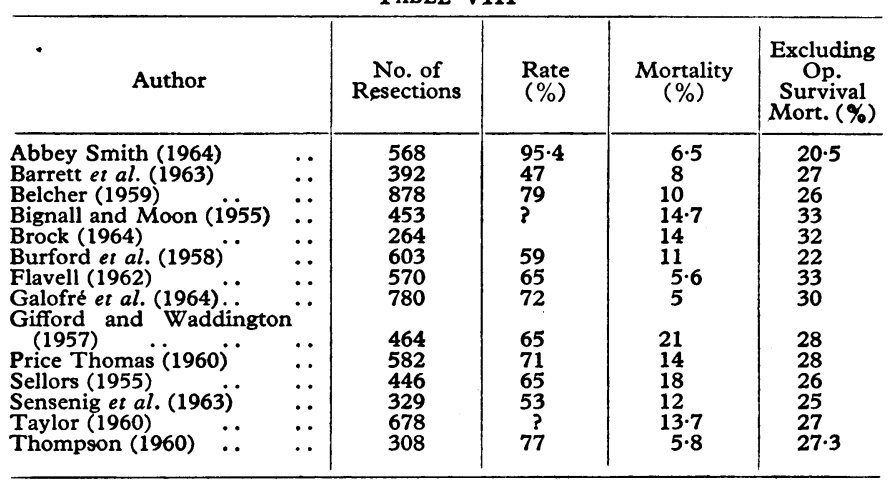

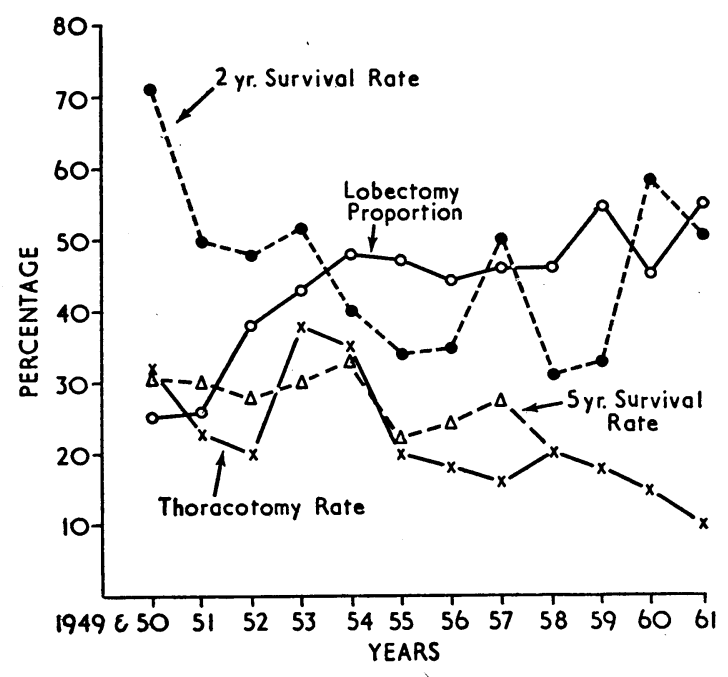

Fig. 6.-Survival rates related to operations done.
In accord with the findings of Siddons (1962) the prognosis has been shown to be similar whatever the cell type of the tumour. Those with adenocarcinomas had the worst outlook, despite the fact that they had a lower rate of glandular involvement. This was also found by Taylor (1960), although Bignall and Moon (1955) and Barrett et al. (1963) recorded a good survival rate in patients with this type of tumour.

In those patients with undifferentiated and oat-cell tumours where resection was possible and there was no glandular involvement the five-year survival rate was the best of the three. As it has been shown that all oat-cell tumours carry a bad prognosis, and as the groups contained approximately $29 \%$ of these tumours (Deal and Belcher, 1963), it seems that the prognosis of the undifferentiated tumours is the best, particularly when resection is possible. The serious significance of glandular involvement was confirmed whatever the cell type.

Lastly, it was hoped that this review might throw more light on the controversy of whether conservatism or radicalism was the right policy in the treatment of bronchial carcinoma (Brock and Whytehead, 1955; Belcher, 1959). The number of patients subjected to either lobectomy or pneumonectomy each year averaged 63, and never fell below 30. The five-year and the two-year survival rates were compared with the proportion of lobectomies done in each year (Fig. 6). This proportion rose steadily from 1949 to 1955 , and then remained fairly steady, exceeding only the proportion of patients having a pneumonectomy in two years. Assuming that the material and the method of selection were similar in each year, then if lobectomy were an inadequate operation the survival rates should have fallen as the proportion of patients having this operation rose. This did not happen; if there was any trend visible it was in the opposite direction. On these grounds the policy of conservatism adopted throughout the series seems to have been justified.

Thus it appears that the pattern of surgically treated bronchial carcinomas has changed little during the last 15 years, the results in terms of operative mortality and survival rates have scarcely improved, and the factors which have been responsible for the great increase in the incidence of the disease have had no influence on the sex incidence or the age incidence, and little influence on the cell type in the patients with carcinoma who have been submitted to surgery.

\section{Summary}

A study of 1,134 patients who have had operations for bronchial carcinoma between 1949 and 1963 has been made.

The operative mortality for resection was $10 \%$, and has changed little during the 15 years. The resectability rate was $79 \% ; 47 \%$ of those who had a resection had a lobectomy. Of those who had a resection and survived their operation, $26 \%$ lived at least five years; those who had a lobectomy had a rate of $29 \%$, and in those with a pneumonectomy it was $24 \%$. The survival rate at 10 years was $16 \%$. Of those in whom a resection was not possible, only $3 \%$ lived more than two years: the average length of survival after thoracotomy was nine months.

There were 92 patients under the age of 45 ; their prognosis was much the same as that of the whole series. The 50 patients over 70 did extremely badly.

There were 115 women operated on ; the proportion of them had not changed significantly during the 15 years.

The cell type of the tumours had changed. The proportion of undifferentiated and oat-celled tumours had risen at the expense of the squamous-cell variety. The proportion of adenocarcinomas had not changed. The cell type made little difference to the survival rate. 
Neither the operative mortality nor the survival rate had changed significantly during the 15 years. The survival rate was not affected by the proportion of lobectomies among the resections, although this had risen considerably during the 15 years.

There was some correlation between the five-year survival rate and the resection rate.

\section{REFERENCES}

Barrett, R. J., Day, J. C., O'Rourke, P. V., Chapman, P. T., Sadeghi, H., Perry, R. W., and Tuttle, W. M. (1963). F. thorac. cardiovasc. Surg., 46, 292.

Belcher, J. R. (1959). Lancet, 2, 639.

Bignall, J. R., and Moon, A. J. (1955). Thorax, 10, 183.

Brock, R. C. (1964). Ann. roy. Coll. Surg. Engl., 35, 195.

- and Whytehead, L. L. (1955). Brit. 7. Surg 43, 8.

Burford, T. H., Ferguson, T. B., and Spjut, H. J. (1958). F. thorac. cardiovasc. Surg., 36, 316.
Clagett, O. T., Allen, T. H., Payne, W. S., and Woolner, L. B. (1964). Ibid., 48,391.

Cotton, R. E. (1959). Brit. F. Dis. Chest, 53, 142.

Crosbie, W. A., Kamdar, H., and Belcher, J. R. (1965). In preparation. Deal, C. W. and Belcher, J. R. (1963). Brit. F. Dis. Chest, 57, 182. Fluvell, (1962). Brit. med.

Flavell, G. (1962). Brit. med. F., 1, 284. B., Clagett, O. T., and Gage, R. P. (1964). Surg. Gynec. Obstet., 119, 51

Gifford, J. H., and Waddington, J. K. B. (1957). Brit. med. f., 1, 723.

Johnston, J. B., and Jones, P. H. (1959). Thorax, 14, 48.

Kreyberg, L. (1952). Acta path. microbiol. scand., Suppl. No. 157.

Kwong, K. H., and Slade, P. R. (1964). Brit. F. Dis. Chest, 58, 124.

MacFarlane, J. C. W., Doughty, B. J., and Crosbie, W. A. (1962). Ibid., $56,57$.

Nohl, H. C. (1956). Thorax, 11, 172.

Nrice Thomas,

Sellors, T. H. (1955). Brit. med. F., 1, 445.

Sensenig, D. M., Rossi, N. P., and Ehrenhaft, J. L. (1963). Surg. Gynec. Obstet., 116, 279.
Sidens,

Siddons, A. H. M. (1962). Thorax, 17, 308.

Smith, R. Abbey (1957). Ibid., 12, 79.

- (1964). F. thorac. cardiovasc. Surg., 48, 418.

Sturridge, M. F. (1964), Personal communication.

Taylor, A. B. (1960). Thorax, 15, 3.

Thompson, V. C. (1960). Ibid., 15, 5.

\title{
Intravenous Regional Analgesia : an Appraisal
}

\author{
BRYAN R. KENNEDY,*† M.B., CH.B., F.F.A. R.C.S. , ASHLEY M. DUTHIE,* M.B., CH.B., D.oBST.R.C.o.G., D.A. ; \\ GEOFFREY D. PARBROOK,* M.B., CH.B., F.F.A. R.C.S. ; T. L. CARR, $\ddagger$ CH.M., F.R.C.S.
}

Brit. med. F., 1965, 1, 954-957

Widespread interest in intravenous regional analgesia was recently revived by Holmes (1963), who described a technique with the advantage of greater simplicity over methods advocated previously.

Although it had been shown by Alms in 1886 (cited by Adams, 1944) that the intravascular injection of a local anaesthetic agent was associated with analgesia in the area supplied by that vessel, this knowledge was not put to practical use until Bier (1908) published his account of venous anaesthesia for limb surgery. His method achieved considerable popularity in the next few years, and its use was widely reported.

Bier's technique, though effective, was cumbersome, and although an improvement in the form of a single-tourniquet method was described by Morrison (1931) few were then employing venous anaesthesia in this country. The subject was well reviewed by Adams (1944), but the credit for the reintroduction of the "technique" undoubtedly goes to Holmes. His series consisted chiefly of relatively short operative procedures of a type suitable for the casualty department. Our aims in the present trial were twofold: (1) to assess the suitability of the method for more extensive limb surgery, and (2) to investigate the incidence and nature of lignocaine toxicity phenomena occurring after release of the tourniquet.

\section{Materials and Method}

The technique described by Holmes was used. An indwelling needle was inserted in a vein before application of an Esmarch bandage and tourniquet. After exsanguination of the limb lignocaine was injected.

Patients due for peripheral limb surgery were interviewed, and, after explanation of the method, were asked whether they would agree to have their operation performed under analgesia of this type. Premedication, usually with an appropriate dose

The Department of Anaesthetics, Aberdeen Royal Infirmary. t Present address: Department of Anaesthetics, Cardiff Royal Infirmary. $\mp$ Consultant Orthopaedic Surgeon, Aberdeen Royal Infirmary. of papaveretum and hyoscine, was given in over three-quarters of the cases. Plate electrodes were attached to each limb in the anaesthetic room and connected to a direct-writing E.C.G. machine. A von Recklinghausen oscillotonometer cuff was put on the arm not scheduled for surgery and the systolic bloodpressure recorded. Difficulty was occasionally experienced through Gordh needles becoming dislodged from veins during application of the Esmarch bandage; polyvinyl chloride catheters inserted through a Macgregor (1960) introducing needle or fine-gauge Intracaths were occasionally used. After injection of the lignocaine and positioning the patient standard lead E.C.G. tracings were obtained. During surgery the bloodpressure was recorded by the oscillotonometer on at least four occasions.

After completion of surgery the tourniquet was deflated and an E.C.G. tracing begun: this ran for two and a half minutes, or longer if any irregularity was noticed. The blood-pressure was recorded at half-minute intervals during this period, and the appearance of the patient was closely observed. Before return to the ward the patients were asked whether they had experienced any symptoms on release of the tourniquet and whether they would have preferred to "be asleep" during surgery. The quality of analgesia and of operating conditions was recorded, as were the time of injection of lignocaine, the time of commencement of surgery, and the time of release of the tourniquet. A specially prepared cyclostyled form was completed with these details plus any other relevant points in every case.

\section{Results}

Intravenous regional analgesia was used in 77 patients. Analgesia was achieved for a wide range of surgical procedures on the hand, including median-nerve decompression, tendon repairs, and digital reconstructive operations. In 46 of the 77 cases E.C.G. records were obtained as described above.

Analgesia.-This was classified as: complete in $78 \%$, good in $7 \%$, moderate in $12 \%$, and poor in $3 \%$. Analgesia was 